Bull. Chem. Soc. Ethiop. 2013, 27(1), 1-13.

Printed in Ethiopia

ISSN 1011-3924

DOI: http://dx.doi.org/10.4314/bcse.v27i1.1

(C) 2013 Chemical Society of Ethiopia

\title{
ASSESSMENT OF THE CONCENTRATION OF Cr, Mn AND Fe IN SEDIMENT USING LASER-INDUCED BREAKDOWN SPECTROSCOPY
}

\author{
Kebede Nigussie Mekonnen ${ }^{1,2}$, Abayneh Ataro Ambushe ${ }^{3,4, *}$, Bhagwan Singh Chandravanshi ${ }^{1}$, \\ Mesfin Redi Abshiro ${ }^{1}$, Anton du Plessis ${ }^{3}$ and Robert Ian McCrindle ${ }^{4}$ \\ ${ }^{1}$ Department of Chemistry, Addis Ababa University, P. O. Box 1176, Addis Ababa, Ethiopia \\ ${ }^{2}$ Department of Chemistry, Mekelle University, P. O. Box 231, Mekelle, Ethiopia \\ ${ }^{3}$ CSIR, National Laser Centre, P. O. Box 395, Pretoria 0001, South Africa \\ ${ }^{4}$ Tshwane University of Technology, Department of Chemistry, \\ P. O. Box 56208, Arcadia 0007, South Africa
}

(Received July 23, 2012; revised October 19, 2012)

\begin{abstract}
In the present study, laser-induced breakdown spectroscopy (LIBS) has been applied for the determination of levels of $\mathrm{Cr}, \mathrm{Mn}$ and $\mathrm{Fe}$ in sediment samples and the results have been compared with that of flame-atomic absorption spectroscopy (F-AAS). Fourteen sediment samples were collected from Tinishu Akaki River (TAR), Addis Ababa, Ethiopia. Pellets of $24 \mathrm{~mm}$ in diameter and 3-5 $\mathrm{mm}$ in thickness were prepared using a manual hydraulic press under a pressure of 8000 psi by mixing finely ground sediment samples with boric acid. The concentrations of $\mathrm{Cr}, \mathrm{Mn}$ and Fe were successfully determined by Q-switched Nd:YAG laser at $1064 \mathrm{~nm}$. Quantification of these metals was conducted against certified reference materials of sediments and soils. The LIBS results for the elements varied from $0.060-0.707 \mathrm{mg} / \mathrm{g}$ for $\mathrm{Cr}, 0.895-3.64 \mathrm{mg} / \mathrm{g}$ for $\mathrm{Mn}$ and $26.9-71.8 \mathrm{mg} / \mathrm{g}$ for Fe. The F-AAS results varied from $0.061-1.37 \mathrm{mg} / \mathrm{g}$ for Cr, $1.24-4.46 \mathrm{mg} / \mathrm{g}$ for $\mathrm{Mn}$ and $49.0-83.3 \mathrm{mg} / \mathrm{g}$ for Fe. TAR was found to be heavily polluted with $\mathrm{Cr}$.
\end{abstract}

KEY WORDS: Laser-induced breakdown spectroscopy, Chromium, Manganese, Iron, Sediment, Tinishu Akaki River, Ethiopia

\section{INTRODUCTION}

Sediments could be polluted by various means other than natural sources, such as via polluted river water, where the river could be polluted by the waste water outflows, airborne inputs, rainfall, dust precipitation, industrial sludge and transport activities [1]. Determination of the concentration of heavy metals in the sediment is important for assessing the nature and extent to which the aquatic environment is polluted. Furthermore, sediment reflects a record of past pollution since it has the capacity to bind several elements. Heavy metals are also present in natural uncontaminated sediments with dissimilar background concentrations. There is an increasing need to determine the degree of pollution quickly and accurately, in particular heavy metals in sediments. Heavy metal analysis can be carried out using flame-atomic absorption spectrometry (F-AAS), graphite furnace-atomic absorption spectrometry (GF-AAS), inductively coupled plasma-optical emission spectrometry (ICP-OES), inductively coupled plasma-mass spectrometry (ICP-MS), laser-induced breakdown spectroscopy (LIBS), X-ray fluorescence spectroscopy (XRF), electrochemical analysis and neutron activation analysis (NAA) where except LIBS the other techniques are the most commonly used [2-12].

Laser-induced breakdown spectroscopy is an atomic emission spectro-chemical technique useful for the analysis of various samples of environmental and geological interest and can be regarded as a universal sampling, atomisation, excitation and ionisation source, since laserinduced plasmas can be formed in gases, liquids, aerosols, slurries, conducting and nonconducting solid samples [13-19]. The basis for LIBS is a solid-state, short-pulsed, Nd:YAG laser that is focused on a sample to produce a high-temperature plasma, high electron density

*Corresponding author. E-mail: abayneh.ataro@gmail.com 
laser spark or microplasma. Upon cooling, the excited atomic, ionic and molecular fragments produced within the plasma emit radiation over a broad spectral range, from UV through visible to the near IR. This reflects the elemental composition of the material in the volatilised sample that can be gated off by the detection system [14, 15, 17, 20-23]. In this technique, powerful laser pulses evaporate a small amount of material (typically a few micrograms) during analysis creating a plasma plume. The emission from the plasma is spectrally resolved to determine the chemical composition of the sample. A range of processes such as sample heating, phase change, melting, atomisation, excitation, ionisation and thermo-ionic emission occurs [14-17, $19,24]$. The technique has proven capable of detecting many metals of environmental concern [23].

The key factors, which can affect the sensitivity of the LIBS system include the laser pulse characteristics (pulse width, energy, etc.), the sample homogeneity and the sampling geometry (distance from the focusing lens to the sample, focal length of the collecting lens, fiber optics, etc.), surrounding atmosphere and the binding material used for the pellet preparation of samples in powder forms [13, 16, 22, 25]. The application of LIBS to sediment samples has advantages such as rapid analysis technique, requires no or little sample preparation (except homogenisation and pellet preparation), portable, possibility of remote sensing and stand-off detection $[20,24,26]$.

Currently, environmentally benign methods are important since they lead to cleaner environment. Due to this reason, methods that avoid acid digestion procedures or minimise excessive sample pre-treatment should be used as this would minimise the level of pollution. Direct solid analysis of environmental samples such as sediment by LIBS was selected as the alternative technique to be evaluated for the determination of heavy metals in sediment. The application of LIBS in the characterisation of heavy metals in sediment as reported in the literature are limited to a few applications [27-30]. Lazic et al. [27], Barbini et al. [28] and Lazic et al. [29] used LIBS for the determination of $\mathrm{Cr}, \mathrm{Cu}, \mathrm{Mn}, \mathrm{Fe}, \mathrm{Ba}$ and other metals in marine sediment samples. Similarly, Mohamed and Askar [30], Capitelli et al. [31], Santos et al. [32] and Senesi et al. [33] determined heavy metals (V, Cr, Mn, Fe, Ni, Co, Cu, Zn, Pb and Cd) in soil and sediment using LIBS.

Both $\mathrm{Fe}$ and $\mathrm{Mn}$ result in the coloration of the water where Fe results in red and brown color while $\mathrm{Mn}$ results in black due to the precipitation of their hydroxides. The colored water may stain textile and fixtures that can cause permanent damage on industrial boilers, equipment and tools which could lead to high consumption of energy because of the insulation caused by minerals (like $\mathrm{Fe}$ and $\mathrm{Mn}$ ) present in water and hence reduces efficiency and life of the equipment $[34,35]$. Both Fe and Mn produce odor and offensive taste that may affect animal intake [36] and their oxides play important role in the soil for fixing trace elements such as Co, $\mathrm{Ni}$ as well as pollutants like $\mathrm{Pb}$ [37]. Although $\mathrm{Fe}$ is an essential element for life, its excess in plant tissues may be responsible for a wide range of metabolic disorders, due mainly to its involvement in Fenton reaction leading to the production of high levels of toxic hydroxyl radicals and other reactive species [38]. Cr is an analyte of interest to the above industries and in the environment because, like other metals, it is not biodegradable. Once it enters the environment, its toxicity is determined to a large extent by its chemical form. Hexavalent $\mathrm{Cr}$ is much more toxic than trivalent $\mathrm{Cr}$ [39]. $\mathrm{Cr}(\mathrm{VI})$ is widely known to cause allergic dermatitis, as well as toxic and carcinogenic effects in humans and animals. Soluble and insoluble $\mathrm{Cr}$ (VI) salts have been demonstrated to induce morphological and neoplastic transformation and mutagenicity in murine and human cells [40].

The objective of this study was to quantify $\mathrm{Cr}, \mathrm{Mn}$ and $\mathrm{Fe}$ in sediment samples collected from Tinishu Akaki River (TAR), Addis Ababa, Ethiopia using LIBS, and to evaluate how different areas of TAR are polluted with regard to $\mathrm{Cr}$, Mn and Fe. For this purpose, sediment samples were collected from fourteen different sites, targeting point and non-point sources of 
pollution in the study area. F-AAS was also used for analysis of the same sediment samples to compare the results.

\section{EXPERIMENTAL}

\section{Chemicals and reagents}

For preparation of pellets, boric acid (Merck, Germany) was used as binder and $\mathrm{Cr}, \mathrm{Mn}$ and $\mathrm{Fe}$ metal powders with high purity $(99.99 \%)$ (Alfa Aesar ${ }^{\circledR}$ A Johnson Matthey Company, USA) were used to identify emission lines of the analytes. The following soil and sediment certified reference materials were used for construction of calibration curves for LIBS analysis and for quality control: Certified Reference Material BCR ${ }^{\circledR}-320$ R No. 58 (IRMM, Belgium), San Jaoquin Soil Standard Reference Material ${ }^{\circledR}$ 2709a (NIST, Gaithersburg, MD, USA), Standard Reference Material ${ }^{\circledR} 2587$ Trace Elements in Soil containing Lead from Paint (NIST, Gaithersburg, MD, USA), Reference Material ${ }^{\circledR} 8704$ Buffalo River Sediment (NIST, Gaithersburg, MD, USA), NCS DC 73322 Soil (China National Analysis Center for Iron and Steel, Beijing, China) and NCS DC 73374 Stream Sediment (China National Analysis Center for Iron and Steel, Beijing, China). For F-AAS analysis, 37\% hydrochloric acid (Puriss, SigmaAldrich, Germany) and 69.5\% nitric acid (Scharlau, reagent grade, ACS, ISO, Spain) were used for digestion of sediment samples. For construction of calibration curves for F-AAS analysis $1000 \mathrm{mg} / \mathrm{L}$ of standard stock solutions of $\mathrm{Cr}, \mathrm{Mn}$ and Fe (Spectra AA - 20 plus, Varian Mulgrave Victoria, Australia) were used after appropriate dilution.

Study area, sample collection and pretreatment

In Addis Ababa, the capital city of Ethiopia, the rapid population expansion, uncontrolled urbanisation and industrialisation, poor sanitation situation and uncontrolled waste disposal causes serious quality deprivation of surface and groundwater. Two major rivers flow through the city, namely Tinishu Akaki and Tiliku Akaki Rivers. Tinishu Akaki basin has a catchment area of about $540 \mathrm{~km}^{2}$ and served as natural sewage lines for domestic and industrial wastes. A total of fourteen sampling sites (TAR at Biheiretsigie, Bulbula River, Gefersa, Kidanemihret River, Melkaqurani River, TAR at Alert area, TAR after mixing with Kidanemihret River, TAR after mixing with Melkaqurani River, TAR before mixing with Kidanemihret River, TAR before mixing with Melkaqurani River, Kebena River, Kera River, TAR at Kalti and TAR at Kolfe) were selected. The sampling stations were chosen to include hotspots of pollution around Addis Ababa city such as an industrial region, uncontrolled domestic wastewater discharge areas and rivers. Sediment samples were collected using ekman grab sampler at shallow depth from TAR and placed in double cap polyethylene bottles to avoid any type of external mixing or moisture. The collected sediment samples were air dried, homogenised using an agate mortar and pestle and passed through a 100-mesh sieve and transferred to polyethylene bottles for storage. The samples were sieved to remove coarse materials because the particles above 100 microns may consist of shells, rocks, wood and other detrital materials. In addition large debris, shells and visible organisms were removed prior to grinding.

\section{LIBS instrumentation}

To carry out LIBS analysis, all fourteen sediment samples were dried and ground to suitable mesh size for pellet preparation. About $4 \mathrm{~g}$ of the sediment samples were accurately weighed and mixed thoroughly with about $0.3 \mathrm{~g}$ of boric acid as binder so as to ensure homogeneity. Care was taken to avoid any contamination due to mixing of other species during the pellet formation process. The pellets were made in a disc of cylindrical form having diameter $24 \mathrm{~mm}$ 
and $3-5 \mathrm{~mm}$ thick using a hydraulic press (ENERPAC P142, International Crystal Laboratories, USA) with pressure of 8000 psi in order to ensure good mixing and homogeneity. Pellets of pure metal powders and certified reference materials were also prepared in similar way for identifying the emission lines and calibration purpose. A Q-switched Nd:YAG laser (Continuum Powerlite 9010, Continuum Inc., Santa Clara, USA) that can deliver a maximum pulse energy of $1 \mathrm{~J}$ operating at its fundamental wavelength $(1064 \mathrm{~nm})$ with pulse duration of 8 ns and $10 \mathrm{~Hz}$ pulse repetition rate was used for generating the sample plasma. The operating conditions for the LIBS system are summarised in Table 1. An energy meter (FieldMax ${ }_{I I}$-TOP, COHEREnT $^{\circledR}$, Portland, OR, USA) was used to monitor the dependence of the LIBS signal on incident laser energy. The laser beam was focused on the samples using a focusing lens of 25.4 $\mathrm{mm}$ diameter and $45 \mathrm{~mm}$ focal length to produce the plasma. In this experiment, a $2 \mathrm{~mm}$ diameter aperture was placed in the path of the laser beam before the lens in order to obtain a uniform beam shape. The emitted light was collimated by collecting lenses at a $45^{\circ}$ angle to the incident laser beam, and thereafter a $2 \mathrm{~m}$ length fused-silica optical fiber was used to feed into an Andor Shamrock SR-303i spectrometer (Model SR-3031-A, Andor Technology, Ireland), equipped with an intensified charge coupled device (DH734-18F-03 ICCD, Andor Technology, Ireland) for detection of the dispersed light containing three different gratings $(300,1200$ and 2400 grooves per $\mathrm{mm}$ ), each one being blazed at $300 \mathrm{~nm}$. An accumulation of 25 laser shots were recorded to complete one measurement so as to enhance the signal-to-background ratio. At least eight spectra of each sample were collected in eight different test portions of the pellet and averaged to decrease the shot-to-shot variations. All the spectral lines for the $\mathrm{Cr}, \mathrm{Mn}$ and $\mathrm{Fe}$ were recorded for pellets of the metal powders and the certified reference materials and were identified using the NIST atomic spectral database. A schematic diagram of the experimental set-up is shown in Figure 1.

Table 1. Operating conditions of Q-switched Nd:YAG laser high power LIBS.

\begin{tabular}{|l|l|l|l|}
\hline \multirow{2}{*}{ Operating parameters } & \multicolumn{2}{|c|}{ Setting for } \\
\cline { 2 - 4 } & $\mathrm{Cr}$ & $\mathrm{Mn}$ & $\mathrm{Fe}$ \\
\hline Laser pulse energy, $\mathrm{mJ}$ & 53.5 & 53.5 & 53.5 \\
\hline Gate delay, $\mu \mathrm{s}$ & 0.9 & 1.4 & 1.0 \\
\hline Gate width, $\mu \mathrm{s}$ & 6 & 6 & 6 \\
\hline Gain level & 150 & 150 & 100 \\
\hline Number of accumulation & 25 & 25 & 25 \\
\hline Grating groove density, lines/mm & 2400 & 2400 & 2400 \\
\hline Grating blaze, nm & 300 & 300 & 300 \\
\hline Input side slit width, $\mu \mathrm{m}$ & 50 & 50 & 50 \\
\hline Wavelength range, $\mathrm{nm}$ & $423-431$ & $402-406$ & $402-410$ \\
\hline
\end{tabular}

Optimisation of LIBS parameters

The experimental variables that can influence LIBS measurements are laser related (i.e. wavelength, energy, pulse duration and shot-to-shot power fluctuation), focusing spot size, ambient conditions, physical properties of the sample, amplification detector gain, ambient atmosphere, pressure and the detection window (delay time and gate width) [41]. The spectrometer was wavelength calibrated using mercury-argon lamp. Using metal powders emission lines with no or minimal interferences were selected. Moreover, pre-exposure was performed to set the response of the ICCD so that the camera would not over-saturate. For each new sample, before spectral collection, 10 laser pulses were performed to clean the sample surface and remove contamination. The delay times were chosen according to the maximum 
LIBS signal intensity for each element present in the samples. Emission spectra at different laser energies were recorded to study the effect of the laser energy on the line emission intensity at a constant gate width of $6 \mu$ s used throughout the study. To study the effect of laser energy on the line emission variation, laser produced plasma emission spectra from sediment samples were recorded from 20-190 $\mathrm{mJ}$ at the optimised delay times for each element.

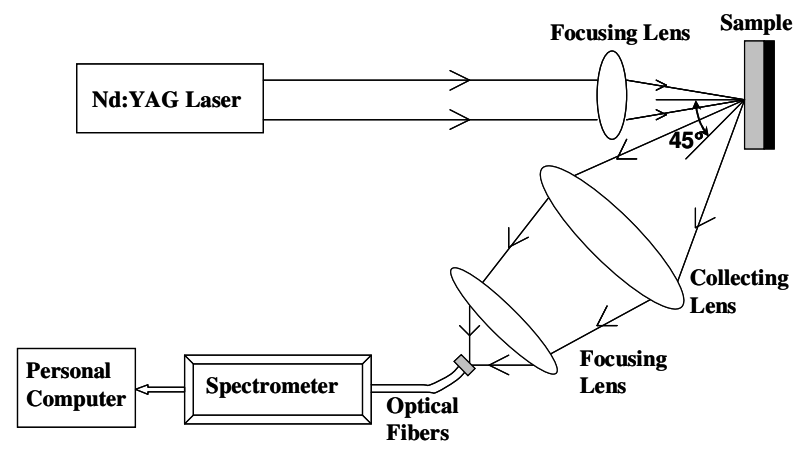

Figure 1. Schematic diagram of LIBS setup.

Digestion of sediment samples for F-AAS

For comparison, samples were also subject to acid digestion and the resulting solutions were analysed by F-AAS. Samples were prepared in triplicate according to the following procedure: about $0.5 \mathrm{~g}$ of dried and ground sediment samples was accurately weighed and placed in 100$\mathrm{mL}$ beaker. Freshly prepared aqua regia $(5 \mathrm{~mL})$ was added. After the completion of the reaction, it was refluxed on a hot plate for $2 \mathrm{~h}$ at a temperature not exceeding $160{ }^{\circ} \mathrm{C}$. The digest was filtered with No. 42 Whatman filter paper after cooling, diluted with deionised water to $50 \mathrm{~mL}$ and placed in the refrigerator prior to analysis using the F-AAS. Blanks were determined in similar fashion and all measurements were done in triplicate. For the calibration curve, a series of working standard solutions of metals $(0,1,2,5$ and $10 \mathrm{mg} / \mathrm{L}$ for $\mathrm{Cr} ; 0,2.5,5,10$ and 20 $\mathrm{mg} / \mathrm{L}$ for $\mathrm{Mn}$; and $0,10,50,100$ and $200 \mathrm{mg} / \mathrm{L}$ for $\mathrm{Fe}$ ) were prepared by appropriate dilution with deionised water of the metal stock solutions of $1000 \mathrm{mg} / \mathrm{L}$. The concentrations of $\mathrm{Cr}, \mathrm{Mn}$ and $\mathrm{Fe}$ in the acid digested sediment samples were determined by F-AAS analysis, Varian Atomic Absorption Spectrometer (Spectra AA - 20 plus, Varian Mulgrave Victoria, Australia). The Buffalo River Sediment Reference Material ${ }^{\circledR} 8704$ (NIST, Gaithersburg, MD, USA) was used for quality control purposes so as to monitor the accuracy of the F-AAS measurements.

\section{RESULTS AND DISCUSSION}

\section{Optimisation of experimental conditions}

In order to enhance the sensitivity of the LIBS for analysing sediment samples, important experimental parameters such as laser pulse energy, gate delay time, gate width and gain level were investigated (Table 1). The spectrometer requires periodic internal calibration using mercury-argon lamp since the spectrum shifts due to variations in laboratory conditions [18]. Additionally, so as to obtain improved results, emission lines with no or minimal interference, due to the sample matrix and lines giving maximum signal intensity for metal powders were selected. The NIST atomic spectral database [42] was also used to identify all the spectral lines 
recorded for analytes using the LIBS system. The most intense wavelength for each element was selected to study the effect of different experimental parameters. For quantification purpose, the selected wavelengths for $\mathrm{Cr}, \mathrm{Mn}$ and $\mathrm{Fe}$ were 425.43, 403.076 and $404.58 \mathrm{~nm}$, respectively. These emission lines had minimal interference from other emission lines.

In the early stages of plasma radiance, an intense continuum emission resulted and after an appropriate delay the plasma cooled to the point where atomic and ionic emissions could be observed. Hence, the study of delay time was fundamental and chosen according to the maximum LIBS signal intensity for each element present in the samples. The delay time with respect to the laser pulse had to be optimised to cut the continuum radiation. A typical plot of the dependence of LIBS signal intensity at the selected wavelengths on delay time, are presented in Figure 2. It is clear from the figure that the maximum LIBS signals are recorded at around 0.9 $\mu \mathrm{s}, 1.4 \mu \mathrm{s}$ and $1.0 \mu \mathrm{s}$ for $\mathrm{Cr}, \mathrm{Mn}$ and $\mathrm{Fe}$, respectively, where maximum signal intensity-tobackground ratios were observed.

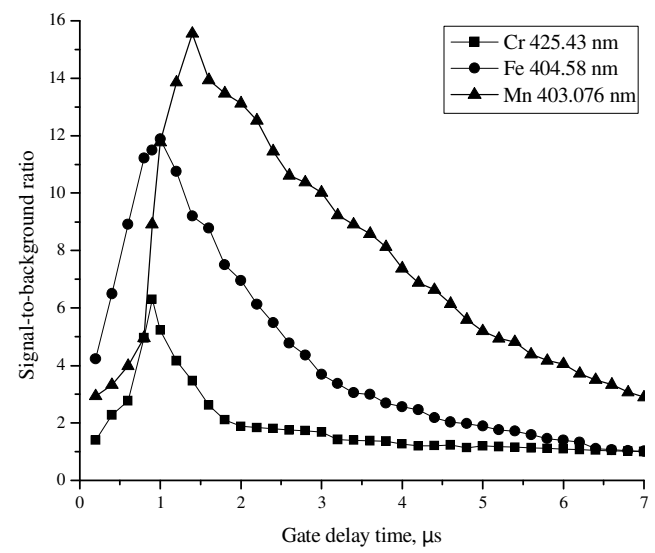

Figure 2. Dependence of LIBS signal intensity on gate delay time for $\mathrm{Cr}, \mathrm{Mn}$ and $\mathrm{Fe}$ in sediment samples.

In LIBS, to produce the plasma and to excite the sample species into ionic and neutral atom electronic transitions, high-pulse energy of the laser beam is required. When a high-energy laser pulse is focused on a sample, the laser energy is deposited on a small area where local temperature rapidly rises above the vaporisation temperature and a laser-induced spark forms at the sample surface. The material is ablated and then atomised in the laser plasma [20]. Furthermore, the signal of the analyte lines is proportional to the laser energy. Emission spectra at different laser energies were recorded to study its effect on the line emission intensity at a constant gate width. The best signal-to-background ratio of analyte lines in sediment sample was obtained at laser pulse energy of about $53.5 \mathrm{~mJ}$ (Figure 3). The laser energy of $53.5 \mathrm{~mJ}$ was selected for subsequent analysis in all the cases (Table 1). The binding materials play an important role in efficiently coupling the laser energy to the sample, ablating a measurable quantity of mass, reducing fractionation and deviation between measurements [16]. Hence boric acid was used as binding material. 


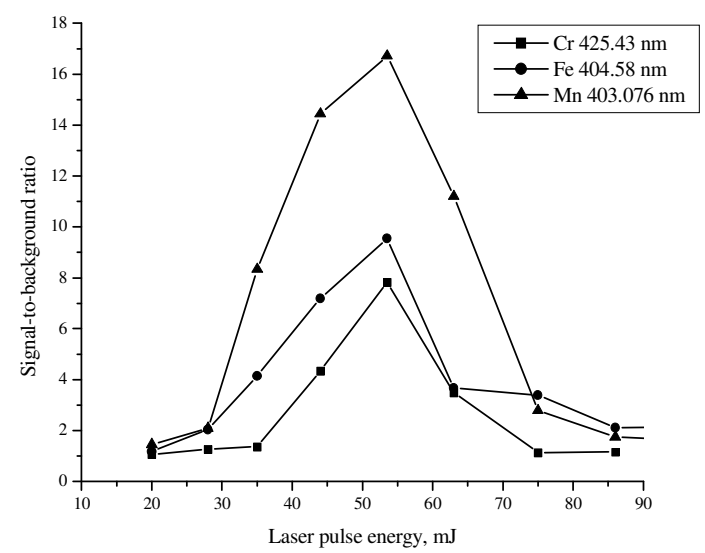

Figure 3. Effect of variation of laser pulse energy on the signal-to-background ratio of $\mathrm{Cr}, \mathrm{Mn}$ and Fe lines of sediment samples.

Spectral analysis

Portions of the spectra of $\mathrm{Cr}, \mathrm{Mn}$ and Fe metal powder standard, sediment samples and certified reference material are presented in Figures 4a-c. In the Figures, the spectra of metal powder were overlaid on to the spectra recorded for sediment samples in order to identify the prominent emission lines of the analytes. Additional lines due to the presence of other elements exist in the selected wavelength region; however, for this study, the best lines of the elements of interest are indicated. There are three strong emission lines of $\mathrm{Cr}$, namely at $425.4 \mathrm{~nm}, 427.4 \mathrm{~nm}$ and 428.9 $\mathrm{nm}$; four strong emission lines of Mn, namely at $403.076 \mathrm{~nm}, 403.3 \mathrm{~nm}, 403.4 \mathrm{~nm}$ and 404.136 $\mathrm{nm}$; and two strong emission lines of Fe, namely at $404.58 \mathrm{~nm}$ and $406.357 \mathrm{~nm}$ [42]. Actually, the line at $425.4 \mathrm{~nm}, 403.076 \mathrm{~nm}$ and $404.58 \mathrm{~nm}$ exhibited highest intensity as shown in Figures 4a-c and were therefore selected for $\mathrm{Cr}, \mathrm{Mn}$ and $\mathrm{Fe}$, respectively, for this study. As it is known, spectral interference is the most severe problem for quantification due to interferences from the emission lines of other atoms. Thus, the above lines were chosen for the determination since they had minimal interferences from emission lines of other elements and are sufficiently intense.

\section{LIBS calibration}

The LIBS system should be calibrated prior to its application for the determination of heavy metals in sediment samples. The most common method for the calibration of a LIBS system for quantitative analysis is by measuring the spectral intensity at the most intense wavelength of that element with certified reference material after identifying the wavelengths using metal powders. Certified reference materials of soil and sediment were employed for construction of calibration curves. The calculations were based on the peak height measured at the selected wavelength of $\mathrm{Cr}$ line $(425.4 \mathrm{~nm})$, Mn line $(403.076 \mathrm{~nm})$ and Fe line $(404.58 \mathrm{~nm})$. The linear regression coefficient $(\mathrm{R})$ values for all calibration curves were greater than 0.998 , which showed strong linear dependence of the LIBS signal on the concentration of analytes and was acceptable for quantitative analysis. 
Kebede Nigussie Mekonnen et al.
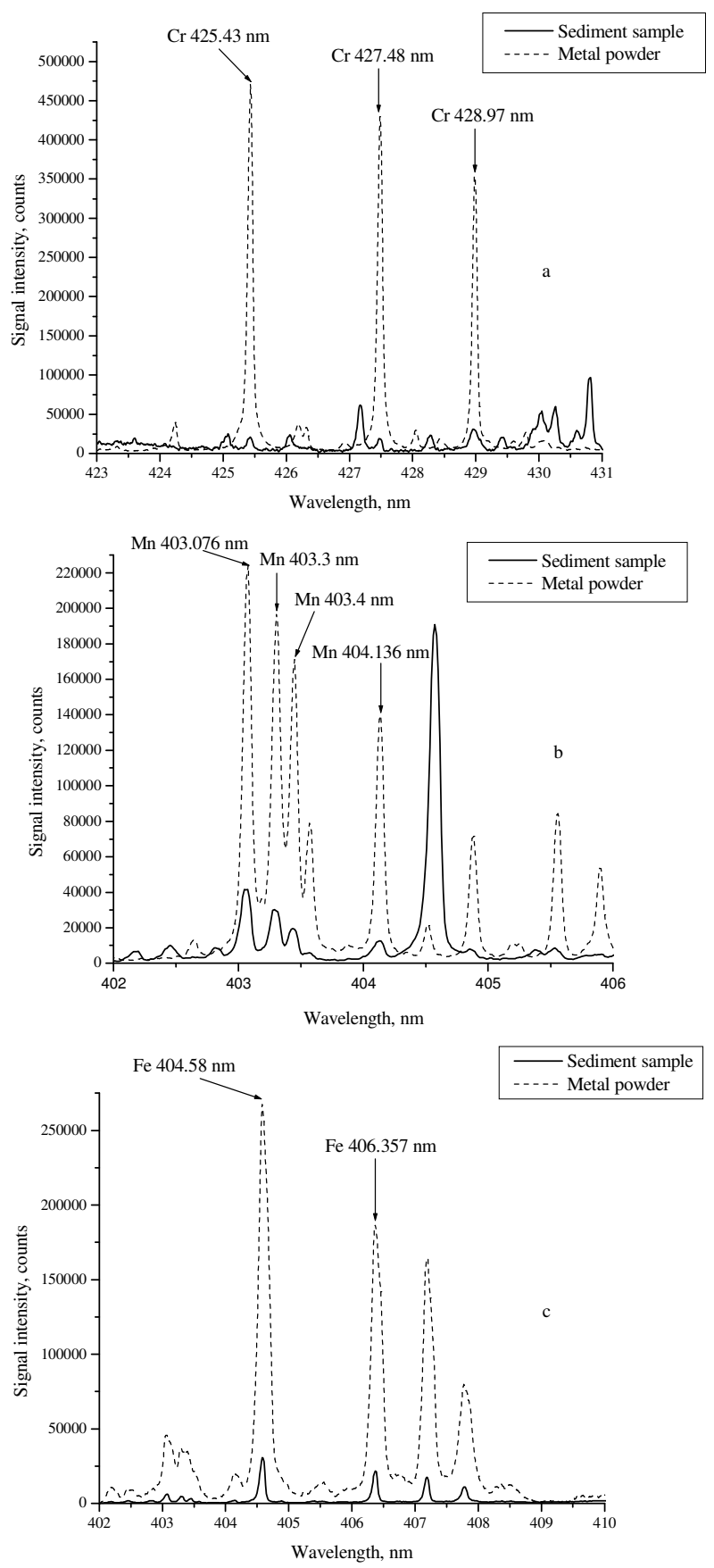

Figure 4. LIBS spectra of $\mathrm{Cr}$ (a), Mn (b) and Fe (c) in sediment samples and metal powders where corresponding main emission lines labeled.

Bull. Chem. Soc. Ethiop. 2013, 27(1) 


\section{Limit of detection}

The limit of detection of LIBS was calculated based on International Union of Pure and Applied Chemistry (IUPAC) definition using the certified reference materials used for calibration with the lowest concentration (mass fraction) of each analyte [13, 18, 43, 44]. Accordingly it was calculated using the equation: limit of detection (LOD) $=3 \sigma_{\mathrm{b}} / \mathrm{S}$, where $\sigma_{\mathrm{b}}$ is the standard deviation of the background (noise level) and $\mathrm{S}$ is the calibration sensitivity ( $\mathrm{S}=$ slope of the calibration curve) which is the ratio of the line intensity to the concentration. The obtained limit of detection for $\mathrm{Cr}, \mathrm{Mn}$ and $\mathrm{Fe}$ were $0.043 \mathrm{mg} / \mathrm{g}, 0.039 \mathrm{mg} / \mathrm{g}$ and $0.079 \mathrm{mg} / \mathrm{g}$, respectively. Lazic et al. [27] reported limit of detection of $0.375 \mathrm{mg} / \mathrm{g}$ for $\mathrm{Mn}$ in sediment samples, which is 9.6 times higher than the limit of detection achieved in this study.

\section{Quality control}

The accuracy and precision in LIBS depends on the sample homogeneity, sample matrix, particle size and excitation properties of the laser. The self-absorption of emission lines is another impediment for the exact determination of elemental concentration due to nonhomogeneous nature of the plasma. This could lead to non-linearity in LIBS signal intensity when plotted against concentration of the emitting elements and in turn affects the accuracy of quantitative analysis [18, 23]. The RSDs of the methods were $\leq 20 \%$ and $\leq 5 \%$ for LIBS and FAAS, respectively. This shows the poor precision of LIBS compared to F-AAS. This high variation in LIBS measurements can be attributed to the unhomogeneity of the sample or nonuniform distribution of the analytes within the sample, variation in the amount of vaporised mass from shot-to-shot, deviation in laser energy and also changes in the distance between the focal plane and the sample surface [45-47]. The accuracy of the LIBS technique was compared with that of the conventional method, F-AAS using t-test at the $95 \%$ level of confidence. The calculated $p$-values were $0.46,0.37$ and 0.002 for $\mathrm{Mn}, \mathrm{Cr}$ and $\mathrm{Fe}$, respectively, where it can be concluded that the two methods are not significantly different for $\mathrm{Mn}$ and $\mathrm{Cr}$, while were significantly different for Fe. The reason for the observed discrepancies between LIBS and FAAS results could be attributed to the above stated factors and matrix effects (sample-plasma interactions) which in turn could be related to differences in absorptivity, particle size distributions and elemental composition of the evaluated matrices. The Buffalo River Sediment Reference Material $^{\circledR} 8704$ (NIST, Gaithersburg, MD, USA) was used for quality control purposes so as to monitor the accuracy of the F-AAS measurements. Results are presented in Table 2, and demonstrate that for the entire elements the determined results are well in agreement with the certified values.

Table 2. Quality control result (mean \pm standard deviation, $\mathrm{mg} / \mathrm{kg}$ ) for F-AAS using Reference Material ${ }^{\circledR}$ 8704.

\begin{tabular}{|l|l|l|l|l|}
\hline No. & Element & F-AAS reading & Certified value & \% Agreement \\
\hline 1 & $\mathrm{Cr}$ & $111 \pm 5.2$ & $122 \pm 3.8$ & 91.0 \\
\hline 2 & $\mathrm{Mn}$ & $526 \pm 34$ & $544 \pm 21$ & 96.6 \\
\hline 3 & $\mathrm{Fe}$ & $3.74 \pm 1.5$ & $3.97 \pm 1.0$ & 94.1 \\
\hline
\end{tabular}

Elemental analysis of sediment samples

The spectra for sediment samples were recorded under identical experimental conditions to those used for the metal powder and certified reference materials. The selected heavy metals present in the sediment sample were identified and the corresponding concentrations are listed in Table 3. All the data were presented after background correction of the signal intensity of the 
sediment and certified reference materials. Net line intensities were calculated by subtracting the background intensities from the signal intensities prior to determining the concentrations of the selected elements. Referring Table 3, the concentration of the elements obtained using LIBS varied from $0.060-0.707 \mathrm{mg} / \mathrm{g}$ for $\mathrm{Cr}, 0.895-3.64 \mathrm{mg} / \mathrm{g}$ for $\mathrm{Mn}$, and $26.9-71.8 \mathrm{mg} / \mathrm{g}$ for $\mathrm{Fe}$, while F-AAS results varied from $0.061-1.37 \mathrm{mg} / \mathrm{g}$ for $\mathrm{Cr}, 1.24-4.46 \mathrm{mg} / \mathrm{g}$ for $\mathrm{Mn}$ and 49.0 $83.3 \mathrm{mg} / \mathrm{g}$ for Fe. The mean concentrations of the metals obtained using LIBS were: Cr: 0.259 $\mathrm{mg} / \mathrm{g}$; Mn: $1.95 \mathrm{mg} / \mathrm{g}$; and Fe: $52.4 \mathrm{mg} / \mathrm{g}$, while the results obtained using F-AAS were: Cr: $0.369 \mathrm{mg} / \mathrm{g}$; Mn: $2.15 \mathrm{mg} / \mathrm{g}$; and Fe: $67.4 \mathrm{mg} / \mathrm{g}$ as summarised in Table 4. In general, areawise comparison shows that areas where less number of industries (such as Biheretsigie and Gefersa) have the lowest concentration while areas where large number of industries (such as AA TAR Kolfe and AA Melkaqurani) have the highest concentrations of the selected metals which indicate an increase in anthropogenic effects around the areas. Melaku et al. [5] determined selected heavy metals including $\mathrm{Cr}$ and $\mathrm{Mn}$ in sediment samples collected from TAR by ICPMS. The reported values ranged from $0.061-16.3 \mathrm{mg} / \mathrm{g}$ and $1.20-6.48 \mathrm{mg} / \mathrm{g}$, for $\mathrm{Cr}$ and $\mathrm{Mn}$, respectively. These are comparable with results found in this study.

Table 3. Concentration of $\mathrm{Cr}, \mathrm{Mn}$ and $\mathrm{Fe}$ (mean \pm standard deviation, in $\mathrm{mg} / \mathrm{g}$ ) in sediment samples from Tinishu Akaki River determined with LIBS and F-AAS.

\begin{tabular}{|l|c|c|c|c|c|c|}
\hline \multirow{2}{*}{ Sample site name } & \multicolumn{2}{|c|}{ Cr concentration } & \multicolumn{2}{c|}{ Mn concentration } & \multicolumn{2}{c|}{ Fe concentration } \\
\cline { 2 - 7 } & LIBS & AAS & LIBS & AAS & LIBS & AAS \\
\hline AA* Biheretsigie & $0.060 \pm 0.012$ & $0.116 \pm 0.006$ & $0.895 \pm 0.027$ & $1.88 \pm 0.10$ & $37.1 \pm 2.7$ & $52.4 \pm 091$ \\
\hline AA Bulbula & $0.072 \pm 0.001$ & $0.137 \pm 0.005$ & $17.0 \pm 0.23$ & $1.64 \pm 0.015$ & $63.9 \pm 3.7$ & $64.0 \pm 1.1$ \\
\hline AA Gefersa & $0.110 \pm 0.008$ & $0.086 \pm 0.004$ & $1.99 \pm 0.25$ & $2.05 \pm 0.043$ & $40.7 \pm 0.66$ & $71.0 \pm 0.61$ \\
\hline AA Kebena & $0.116 \pm 0.004$ & $0.170 \pm 0.002$ & $1.86 \pm 0.30$ & $1.88 \pm 0.032$ & $42.1 \pm 3.8$ & $53.3 \pm 0.59$ \\
\hline AA Kera & $0.138 \pm 0.017$ & $0.147 \pm 0.008$ & $1.91 \pm 0.21$ & $1.83 \pm 0.043$ & $69.5 \pm 11$ & $76.2 \pm 1.3$ \\
\hline AA Kidanemihret & $0.181 \pm 0.036$ & $0.181 \pm 0.003$ & $1.29 \pm 0.19$ & $1.24 \pm 0.026$ & $26.9 \pm 0.78$ & $49.0 \pm 0.57$ \\
\hline AA Melkaqurani & $0.082 \pm 0.001$ & $0.061 \pm 0.003$ & $3.64 \pm 0.73$ & $4.46 \pm 0.22$ & $58.4 \pm 2.5$ & $65.1 \pm 3.26$ \\
\hline AA TAR Alert & $0.517 \pm 0.084$ & $0.591 \pm 0.020$ & $2.03 \pm 0.34$ & $1.97 \pm 0.035$ & $53.4 \pm 4.8$ & $73.0 \pm 0.88$ \\
\hline $\begin{array}{l}\text { AA TAR and } \\
\text { Kidanemihret }\end{array}$ & $0.238 \pm 0.048$ & $0.182 \pm 0.003$ & $1.96 \pm 0.14$ & $2.01 \pm 0.042$ & $52.9 \pm 2.7$ & $69.2 \pm 1.2$ \\
\hline AA TAR and Melkaqurani & $0.199 \pm 0.010$ & $0.209 \pm 0.006$ & $1.87 \pm 0.089$ & $2.85 \pm 0.142$ & $61.2 \pm 8.4$ & $75.0 \pm 2.2$ \\
\hline $\begin{array}{l}\text { AA TAR before } \\
\text { Kidanemihret }\end{array}$ & $0.190 \pm 0.096$ & $0.366 \pm 0.007$ & $2.48 \pm 0.31$ & $2.50 \pm 0.062$ & $71.8 \pm 10$ & $72.0 \pm 0.43$ \\
\hline $\begin{array}{l}\text { AA TAR before } \\
\text { Melkaqurani }\end{array}$ & $0.707 \pm 0.072$ & $1.08 \pm 0.009$ & $1.59 \pm 0.14$ & $1.52 \pm 0.015$ & $40.6 \pm 4.3$ & $65.6 \pm 1.4$ \\
\hline \begin{tabular}{l} 
AA TAR Kalti \\
\hline AA TAR Kolfe
\end{tabular} & $0.385 \pm 0.059$ & $0.481 \pm 0.014$ & $2.07 \pm 0.24$ & $2.23 \pm 0.054$ & $58.7 \pm 5.5$ & $74.9 \pm 2.1$ \\
\hline $\begin{array}{l}\text { AA* Addis Ababa } \\
\text { AA }\end{array}$ & $0.638 \pm 0.066$ & $1.37 \pm 0.014$ & $2.03 \pm 0.35$ & $2.01 \pm 0.026$ & $56.6 \pm 4.0$ & $83.3 \pm 1.2$ \\
\hline
\end{tabular}

Table 4. Summary of the results obtained for the composition of $\mathrm{Cr}$, Mn and Fe in sediment using LIBS and F-AAS.

\begin{tabular}{|l|l|l|l|l|l|l|}
\hline \multirow{2}{*}{ Parameters } & \multicolumn{3}{|c|}{ Element } \\
\cline { 2 - 7 } & \multicolumn{2}{|c|}{ Cr } & \multicolumn{2}{|c|}{ Mn } & \multicolumn{2}{c|}{ Fe } \\
\cline { 2 - 7 } & LIBS & F-AAS & LIBS & F-AAS & LIBS & F-AAS \\
\hline Selected wavelength, nm & 425.43 & 357.9 & 403.076 & 279.5 & 404.58 & 248.3 \\
\hline Limit of detection, mg/g & 0.043 & 0.00012 & 0.039 & 0.00025 & 0.079 & 0.00051 \\
\hline R for calibration curve & 0.9981 & 1 & 0.9989 & 0.9999 & 0.9997 & 0.9997 \\
\hline Minimum concentration, mg/g & 0.060 & 0.061 & 0.895 & 1.24 & 26.9 & 49.0 \\
\hline Maximum concentration, mg/g & 0.707 & 1.37 & 3.64 & 4.46 & 71.8 & 83.3 \\
\hline Average concentration, mg/g & 0.259 & 0.369 & 1.95 & 2.15 & 52.4 & 67.4 \\
\hline RSD & $\leq 20 \%$ & $\leq 5 \%$ & $\leq 20 \%$ & $\leq 5 \%$ & $\leq 20 \%$ & $\leq 5 \%$ \\
\hline Correlation coefficient & 0.94 & -0.06 & & 0.70 & \\
\hline
\end{tabular}

Bull. Chem. Soc. Ethiop. 2013, 27(1) 
Assessment of sediment contamination based on sediment quality guidelines (SQGs)

Numerical sediment quality guidelines (SQGs) have been used to identify contaminants of concern in aquatic ecosystem [48]. Sediments were classified as non-polluted, moderately polluted and heavily polluted, based on SQGs of United State Environmental Protection Agency (USEPA) [49]. The need for chemical guidelines that could be used to predict adverse biological effects in contaminated sediments led to the development of SQGs [50-55]. As can be seen from the results, with reference to sediment quality guidelines (Table 5), TAR is heavily polluted by $\mathrm{Cr}$.

Table 5. Concentration $(\mathrm{mg} / \mathrm{g})$ of heavy metals in the core sediment and its comparison with sediment quality guidelines (SQGs).

\begin{tabular}{|c|c|c|c|c|c|}
\hline Element & $\begin{array}{c}\text { Mean } \\
\text { LIBS }\end{array}$ & $\begin{array}{c}\text { Mean } \\
\text { F-AAS }\end{array}$ & $\begin{array}{c}\text { SQG } \\
\text { non-polluted }\end{array}$ & $\begin{array}{c}\text { SQG } \\
\text { moderate polluted }\end{array}$ & $\begin{array}{c}\text { SQG } \\
\text { heavily polluted }\end{array}$ \\
\hline $\mathrm{Cr}$ & 0.259 & 0369 & $<0.025$ & $0.025-0.075$ & $>0.075$ \\
\hline $\mathrm{Mn}$ & 1.95 & 2.15 & - & - & - \\
\hline $\mathrm{Fe}$ & 5.24 & 6.74 & - & - & - \\
\hline
\end{tabular}

\section{CONCLUSIONS}

The concentration of $\mathrm{Cr}, \mathrm{Mn}$ and $\mathrm{Fe}$ in sediment samples collected from Tinishu Akaki River (TAR), Addis Ababa, Ethiopia was determined using LIBS. The experimental parameters such as laser pulse energy, gate delay time and gate width were investigated, and the optimum parameters that improved the signal-to-background ratio of LIBS measurement were obtained. The LIBS results were compared with those obtained using a standard analytical technique, FAAS. The proposed LIBS procedure is very simple, environmentally friendly and avoids the lengthy and corrosive acid digestion route. This allows for fast analysis and the results showed that LIBS can be applied as an alternative technique to other existing methods, like F-AAS, and does not require a sample decomposition step which is time consuming, expensive and may result in contamination of samples and the environment itself. With reference to SQGs, TAR is heavily polluted with $\mathrm{Cr}$. Areas with less number of industries (such as Biheretsigie and Gefersa) have the lowest concentrations while those with large number of industries (such as AA TAR Kolfe and AA Melkaqurani) have the highest concentrations of the selected metals which indicate an increase in anthropogenic effects around the indicated areas.

\section{ACKNOWLEDGEMENTS}

This work was financially supported by the African Laser Centre (project no. LHEAB01 Task 11 13). The fund from Rental Pool Programme (project no. LREEO00) is duly acknowledged. This research is part of a PhD dissertation, so financial assistance by the Office of Research and Graduate Programs of Addis Ababa University, Ethiopia is gratefully acknowledged. Moreover, the authors acknowledge Department of Chemistry of Addis Ababa University (Ethiopia) and Council for Scientific and Industrial Research (CSIR), National Laser Centre (South Africa) for allowing us to use the laboratory facilities. Kebede Nigussie Mekonnen acknowledges Mekelle University (Ethiopia) for the partial financial support (with project registry number CNCS/RB/21/2010). 


\section{REFERENCES}

1. Ujevic, I.; Odzak, N.; Baric, A. Water Res. 2000, 34, 3055.

2. Patnaik, P. Dean's Analytical Chemistry Handbook, 2nd ed. McGraw-Hill: USA; 2004.

3. Rouessac, F.; Rouessac, A. Chemical Analysis Modern Instrumentation Methods and Techniques, John Wiley and Sons: Chichester; 2004.

4. Sitko, R.; Zawisza, B.; Jurczyk, J.; Buhl, F.; Zielonka, U. Polish J. Environ. Stud. 2004, 13, 91.

5. Melaku, S.; Wondimu, T.; Dams, R.; Moens, L. Can. J. Anal. Sci. Spectrosc. 2005, 50, 31.

6. Ahuja, S.; Jespersen, N. Modern Instrumental Analysis, Vol. 47, Elsevier: Netherlands; 2006.

7. Skoog, D.A.; Holler F.J.; Crouch. S.R. Principles of Instrumental Analysis, 6th ed. Thomson Corporation: Canada; 2007.

8. Chen, D.; Hu, B.; Huang, C. Talanta 2009, 78, 491.

9. Shibata, Y.; Suyama, J.; Kitano, M.; Nakamura, T. X-Ray Spectrom. 2009, 38, 410.

10. Cevik, U.; Kozb, B.; Makarovska, Y. X-Ray Spectrom. 2010, 39, 202.

11. Faraji, M.; Yamini, Y.; Saleh, A.; Rezaee, M.; Ghambarian, M.; Hassani, R. Anal. Chim. Acta 2010, 659, 172.

12. Lepri, F.G.; Borges, D.L.G.; Araujo, R.G.O.; Welz, B.; Wendler, F.; Krieg, M.; BeckerRoss, H. Talanta 2010, 81, 980.

13. Le Drogoff, B.; Margot, J.; Chaker, M.; Sabsabi, M.; Barthelemy, O.; Johnston, T.W.; Laville, S.; Vidal, F.; von Kaenel, Y. Spectrochim. Acta, Part B 2001, 56, 987.

14. Cremers, D.A.; Radziemski, L.J. Handbook of Laser-Induced Breakdown Spectroscopy, John Wiley and Sons: Chichester; 2006.

15. Miziolek, A.; Palleschi, V.; Schechter, I. Laser-Induced Breakdown Spectroscopy (LIBS) Fundamental Applications, Cambridge University Press: New York; 2006.

16. Gondal, M.A.; Hussain, T.; Yamani, Z.H.; Baig, M.A. Talanta 2007, 72, 642.

17. Singh, J.P.; Thakur, S.N. Laser-Induced Breakdown Spectroscopy, Elsevier: Amsterdam; 2007.

18. Mohamed, W.T.Y. Opt. Laser Technol. 2008, 40, 30.

19. Gondal, M.A.; Nasr, M.M.; Ahmed, Z.; Yamani, Z.H. J. Environ. Sci. Health, Part A 2009, 44, 528.

20. Lal, B.; Zheng, H.; Yueh, F.Y.; Singh, J.P. Appl. Opt. 2004, 43, 2792.

21. Gondal, M.A.; Hussain, T.; Yamani, Z.H.; Baig, M.A. Talanta 2006, 69, 1072.

22. Bakry, A.H. Pakistan J. Anal. Environ. Chem. 2007, 8, 7.

23. Gondal, M.A.; Hussain, T.; Yamani, Z.H.; Baig, M.A. J. Hazard. Mater. 2009, 163, 1265.

24. Gondal, M.A.; Nasr, M.M.; Ahmed, M.M.; Yamani, Z.H.; Alsalhi, M.S. J. Environ. Sci. Health, Part A 2011, 46, 42.

25. Gondal M.A.; Hussain, T. Talanta 2007, 71, 73.

26. Liu, X.Y.; Zhang, W.J. J. Biomed. Sci. Eng. 2008, 1, 147.

27. Lazic, V.; Barbini, R.; Colao, F.; Fantoni, R.; Palucci, A. Spectrochim. Acta, Part B 2001, $56,807$.

28. Barbini, R.; Colao, F.; Lazic, V.; Fantoni, R.; Palucci, A.; Angelone, M. Spectrochim. Acta, Part B 2002, 57, 1203.

29. Lazic, V.; Colao, F.; Fantoni, R.; Spizzichino, V.; Jovicevic, S. Spectrochim. Acta, Part B 2007, 62, 30 .

30. Mohamed, W.T.Y.; Askar, A. Prog. Phys. 2007, 1, 46.

31. Capitelli, F.; Colao, F.; Provenzano, M.R.; Fantoni, R.; Brunetti, G.; Senesi, N. Geoderma 2002, 106, 45. 
32. Jr. Santos, D.; Nunes, L.C.; Trevizan, L.C.; Godoi, Q.; Leme, F.O.; Braga, J.W.; Krug, F.J. Spectrochim. Acta, Part B 2009, 64, 1073.

33. Senesi, G.S.; Dell'Aglio, M.; Gaudiuso, R.; De Giacomo, A.; Zaccone, C.; De Pascale, O.; Miano, T.M.; Capitelli, M. Environ. Res. 2009, 109, 413.

34. Katsoyiannis, I.A.; Zouboulis, A.I. Water Res. 2004, 38, 1922.

35. Ghasemi-Fasaei, R.; Ronaghi, A. J. Plant Nutr. 2008, 31, 839.

36. Beutel, M.W.; Leonard, T.M.; Dent, S.R.; Moore, B.C. Water Res. 2008, 42, 1953.

37. Demirezen, D.; Aksoy, A.; Ecol. Indic. 2006, 6, 388.

38. De Dorlodot, S.; Lutts, S.; Bertin, P. J. Plant Nutr. 2005, 28, 1.

39. Gomez, V.; Callao, M.P. Trend. Anal. Chem. 2006, 25, 1006.

40. Bagchi, D.; Stohs, S.J.; Downs, B.W.; Bagchi, M.; Preuss, H.G. Toxicology 2002, 180, 5.

41. Godoi, Q.; Jr. Santos, D.; Nunes, L.C.; Leme, F.O.; Rufini, I.A.; Agnelli, J.A.M.; Trevizan, L.C.; Krug, F.J. Spectrochim. Acta Part B 2009, 64, 573.

42. Ralchenko, Y.; Kramida, A.E.; Reader, J.; NIST ASD Team. NIST Atomic Spectra Database (ver. 4.1.0), [Online]. Available: http://physics.nist.gov/asd3 [2011, June 20]. National Institute of Standards and Technology: Gaithersburg: MD; 2011.

43. Sabsabi, M.; Heon, R.; St-Onge, L. Spectrochim. Acta, Part B 2005, 60, 1211.

44. Dell' Aglio, M.; Gaudiuso, R.; Senesi, G.S.; De Giacomo, A.; Zaccone, C.; Miano, T.M.; De Pascale, O. J. Environ. Monit. 2011, 13, 1422.

45. Rossbach M.; Zeiller, E. Anal. Bioanal. Chem. 2003, 377, 334.

46. Trevizan, L.C.; Jr. Santos, D.; Samad, R.E.; Vieira, N.D.J.; Nomura, C.S.; Nunes, L.C.; Rufini, I.A.; Krug, F.J. Spectrochim. Acta, Part B 2008, 63, 1151.

47. Trevizan, L.C.; Jr. Santos, D.; Samad, R.E.; Vieira, N.D.J.; Nunes, L.C.; Rufini. I.A.; Krug, F.J. Spectrochim. Acta, Part B 2009, 64, 369.

48. McDonald, D.D.; Ingersoll, C.G.; Berger, T.A. Arch. Environ. Contam. Toxicol. 2000, 39, 20.

49. Perin, G.; Bonardi, M.; Fabris, R.; Simoncini, B.; Manente, S.; Tosi, L.; Scotto, S. Environ. Technol. 1997, 18, 593.

50. USEPA (United States Environmental Protection Agency). Sediment Classification Method Compendium, Environmental Protection Agency: Washington DC; 1992.

51. Long, E.R.; Macdonald, D.D.; Smith, S.L.; Calder, F.D. Environ. Manage. 1995, 19, 81.

52. Long, E.R.; Macdonald, D.D. Hum. Ecol. Risk Assess. 1998, 4, 1019.

53. Bakan, G.; Ozkoc, H.B. Int. J. Environ. Stud. 2007, 64, 45.

54. Harikumar, P.S.; Nasir, U.P.; Rahman, M.P.M. Int. J. Environ. Sci. Technol. 2009, 6, 225.

55. Nasir, U.P.; Harikumar, P.S. J. Environ. Prot. 2011, 2, 710. 